\title{
Aigunas consideraciones acerca del Impuesto Municipal sobre Actividades Económicas
}

\author{
Francisco García-Fresneda Gea \\ Profesor de Derecho Financiero y Tributario \\ Facultad de Ciencias Económicas y Empresariales \\ Universidad de Granada
}

Sumario: I. INTRODUCCIÓN. 1. Concepto. 2. Naturaleza jurídica. A. Impuesto directo. B. Impuesto de carácter real. C. Impuesto objetivo. D. Impuesto periódico. E. Impuesto de titularidad municipal. F. Impuesto de exigencia obligatoria. G. Impuesto censal. H. Impuesto de gestión compartida. II. EL OBJETO IMPONIBLE EN EL IAE. III. EL HECHO IMPONIBLE DEL IAE. 1. Definición del hecho imponible. 2. Concepto de actividad económica. 3. Concepto de actividades empresariales, profesionales y artísticas. A. Concepto de actividades empresariales. B. Concepto de actividades profesionales. a) Consideraciones respecto del sujeto que presta el servicio profesional. b) Consideraciones respecto del objeto o naturaleza del servicio profesional. c) Consideraciones respecto de la forma de prestar el servicio profesional. C. Concepto de actividades artísticas. IV. A MODO DE CONCLUSIÓN. 1. El IAE y el principio de capacidad económica. 2. El IAE y el principio de generalidad tributaria. 3. El IAE y el principio de igualdad tributaria. A. Las actividades empresariales, profesionales y artísticas y el principio de igualdad tributaria. B. Los módulos indiciarios y el principio de igualdad tributaria. 4. El IAE y la doble imposición interna. 5. Recapitulación final.

\section{INTRODUCCIÓN}

\section{Concepto}

El Impuesto sobre Actividades Económicas se define por la normativa vigente, artículo 79 de la Ley 39/1988, de 28 de diciembre, Reguladora de las Haciendas Locales (LRHL), como «un tributo directo de carácter real, cuyo hecho imponible está constituido por el mero ejercicio en territorio nacional de actividades empresariales, profesionales o artísticas, se ejerzan o no en local determinado y se hallen o no especificadas en las Tarifas del Impuesto».

El IAE fue creado por la LRHL, formando parte del nuevo sistema impositivo municipal, el cual pretende alcanzar para los Municipios una mayor autonomía y suficiencia recaudatoria '. Los artículos 79 a 92 de la LRHL recogen la regulación esencial de este impuesto, cuya entrada en

' El Real Decreto-Legislativo 1.175/1990, de 28 de septiembre, aprobó las Tarifas del Impuesto sobre Actividades Económicas y la Instrucción para aplicarlas. Por su parte, el Real Decreto-Legis- 
vigor supuso la supresión de la Licencia Fiscal de Actividades Comerciales e Industriales, y de la Licencia Fiscal de Actividades Profesionales y Artísticas, de los Impuestos sobre la Radicación, de la Cuota Fija de la Contribución Pecuaria, y de los Impuestos sobre la Publicidad y sobre Gastos Suntuarios (excepto la modalidad que grava el aprovechamiento de cotos de caza y pesca, la cual se ha mantenido en vigor en virtud del artículo 6 de la Ley 6/1991, de 11 de marzo) ${ }^{2}$.

Resulta incuestionable la importancia del IAE como medio de financiación de las Entidades Locales, no sólo por la simplificación que aporta - puesto que su entrada en vigor ha supuesto la desaparición de los impuestos anteriores-, sino, también, por su carácter obligatorio. Aunque, como ha señalado CHECA GONZÁLEZ, tendrá que ser remodelado en su estructura si se pretende su supervivencia debido a los graves defectos que presenta ${ }^{3}$. Esto es lo que está ocurriendo en otros países en los que existe un impuesto similar, como en Alemania con el Gewerbesteuer y en Francia con la Taxe professionelle ${ }^{4}$.

lativo 1.259/1991, de 2 de agosto, aprobó las Tarifas y la Instrucción del Impuesto sobre Actividades Económicas, correspondiente a la actividad ganadera independiente.

${ }^{2}$ La Ley 44/1978, de 8 de septiembre, del Impuesto sobre la Renta de las Personas Físicas, suprimió la cuota proporcional de la Contribución Pecuaria y configuró su cuota fija como tributo local de carácter real.

Por su parte, el mantenimiento del gravamen de la modalidad del Impuesto sobre Gastos Suntuarios, que grava el aprovechamiento de cotos de caza y pesca, ha tenido lugar como consecuencia de no quedar incluidas en el hecho imponible del IAE las actividades agrícolas, ganaderas dependientes, forestales y pesqueras.

${ }^{3}$ C. CheCA GonzÁlez, «El Impuesto sobre Actividades Económicas», en Impuestos, n. ${ }^{\circ} 23,1989$, p. 7.

${ }^{4}$ Aunque en el Derecho comparado la tendencia sea la desaparición de los impuestos que gravan el mero ejercicio de actividades económicas, dicha tendencia no es general, puesto que existen otros paises de nuestro entorno en los que se ha producido la rehabilitación o creación de impuestos análogos.

Éste es el caso de Italia, donde se ha creado el Impuesto municipal sobre el ejercicio de empresas, artes y profesiones por medio del Decreto Ley de 2 de marzo de 1989, número 66, convertido con modificaciones en la Ley de 24 de abril de 1989, número 144.

GARCía LUIS señala al respecto: «El tributo italiano contempla como hecho imponible el ejercicio de las actividades citadas y recurre también a la misma técnica tarifaria para la determinación de las cuotas, si bien mucho más simplificada que la del IAE, ya que en aquél sólo se tiene en consideración a tal efecto la superficie de los locales en los que se ejerce la actividad, además, claro está, del tipo de actividad desarrollada.

El citado Decreto Ley y la Ley de conversión han rehabilitado el viejo impuesto sobre las industrias, los comercios, las artes y las profesiones regulado en el Texto Único de la Finanza Local (art. 93.1 del Real Decreto de 14 de septiembre de 1931, n. ${ }^{\circ} 1.175$ ) como una figura de implanta- 
El IAE tiene por objeto el gravamen del beneficio presunto de las actividades empresariales, profesionales y artísticas. Se renuncia, de este modo, al gravamen de los beneficios ciertos de las citadas actividades, prevaleciendo, en consecuencia, la comodidad en la determinación de las cuotas y la garantía de la recaudación, frente a la adecuación del impuesto al principio de capacidad económica.

El IAE, sin embargo, pretende aproximar el beneficio presunto de cada actividad económica al beneficio real, con la utilización de una serie de módulos indiciarios, entre los que cabe destacar el módulo indiciario «superficie del local».

\section{Naturaleza jurídica}

La naturaleza jurídica del IAE se establece a partir de las distintas notas que lo caracterizan, bien de manera directa, a través de la normativa que lo regula, o de manera indirecta a través de su contexto. Siguiendo a RUBIO DE URQUÍA, se trata de un impuesto directo, de carácter real, de titularidad municipal, de exigencia obligatoria y de gestión compartida ${ }^{5}$. A lo que se podría añadir su carácter de impuesto objetivo, periódico y censal ${ }^{6}$.

ción facultativa por los distintos Municipios y que fue abolida por el artículo 82.c) del Decreto del Presidente de la República, de 29 de septiembre de 1973, n. ${ }^{\circ} 579$. Mediante el Decreto Ley de 30 de septiembre de $1989, \mathrm{n}^{\circ} 322$, convertido con modificación en la Ley de 27 de noviembre de 1989 , n. ${ }^{\circ} 384$, el impuesto actual ha sufrido modificaciones importantes, entre las que destaca la posibilidad, antes inexistente, de duplicar o reducir a la mitad el importe derivado de la aplicación de su tarifa en función de la renta efectiva o declarada a los efectos del impuesto sobre la Renta de las Personas Físicas o sobre la renta de las personas jurídicas». Véase: T. GARCta Luss, «Impuesto sobre Actividades Económicas", en R. Calvo OrTEga y otros: La Reforma de las Haciendas Locales, vol. I, Ed. Lex Nova, Valladolid, 1991, p. 441.

5 J. I. Rubio de Urquí, El Impuesto sobre Actividades Económicas, Ed. Abella, Madrid, 1990, pp. 52 y ss.

${ }^{6}$ Otra de las características predicables del IAE es que se trata de un impuesto nuevo pero de refundición. En efecto, aunque el LAE herede la mayor parte de sus elementos estructurales de una serie de impuestos anteriores - Licencias Fiscales y Radicación, principalmente- no cabe duda que se trata de un nuevo impuesto y no de una simple refundición de los citados impuestos, lo cual produce una desvinculación formal del IAE respecto de aquéllos. Esta calificación se corrobora con el amplio periodo transitorio hasta su entrada en vigor, circunstancia ésta que se puede considerar normal en los tributos nuevos pero no en los que, simplemente, han sido reformados. Además, no se produce ninguna remisión a la normativa anterior que regulaba los citados impuestos, excepto las de carácter transitorio (véase Disposición Transitoria 3. y Disposición Derogatoria LRHL).

Por otra parte, ni siquiera se aprovechó el censo que existía de Licencias Fiscales adaptándolo al IAE. Se optó, en cambio, por la elaboración de un nuevo censo antes de su entrada en vigor. Sin embargo, aunque el IAE sea un tributo nuevo y no se pueda utilizar la normativa anterior, esto no impide -puesto que emplea elementos de los anteriores impuestos - la utilización de criterios doctri- 


\section{A. Impuesto directo}

El artículo 79.1 de la LRHL dispone: «El Impuesto sobre Actividades Económicas es un tributo directo de carácter real» ${ }^{7}$. Consideramos acertada la naturaleza de impuesto directo del IAE, puesto que concuerda con cualquiera de los criterios que utiliza la doctrina para la distinción de impuestos directos e indirectos. De acuerdo con el primer criterio o teoría, es decir, aquella que parte de la modalidad de riqueza que se pretende gravar, serían impuestos directos los que gravan manifestaciones de capacidad económica que se ponen de relieve de manera inmediata y directa. A nuestro juicio, existen únicamente tres indicadores de capacidad económica: la obtención de ingresos, la titularidad de un patrimonio y el tráfico patrimonial. Siendo indicadores directos los dos primeros e indicador indirecto el tercero ${ }^{8}$. En consecuencia, al ser el objeto imponible del IAE el rendimiento de la actividad (rendimiento presunto), se trata de un indicador directo de capacidad económica, siendo, por tanto, correcta su calificación de impuesto directo.

De acuerdo con el segundo criterio o teoría, se parte de los diferentes métodos de imposición. En ciertas ocasiones el legislador faculta o impone al sujeto pasivo la obligación de obtener el reembolso de lo pagado de otra persona que no forma parte de la relación jurídica tributaria, tratándose entonces de un impuesto indirecto. Mientras que cuando no se otorgan las facultades legales para resarcirse del impuesto pagado estaríamos ante un impuesto directo. Según esta teoría, el IAE también sería un impuesto directo, debido a que, a los sujetos pasivos del mismo, en ningún caso se les faculta o se les obliga de forma legal a repercutir el importe de las cuotas sobre terceros ajenos a la relación jurídica tributaria ${ }^{9}$.

nales y jurisprudenciales surgidos de los impuestos anteriores, siempre, por supuesto, que no contradigan la normativa vigente.

7 Debemos destacar la falta de técnica legislativa en la que incurre el anterior precepto, tal y como ha señalado, entre otros, Albiñana Garcia-QunTANa, puesto que los tributos no se pueden calificar de directos, ni de indirectos, al estar incluidos dentro de ellos no sólo los impuestos, sino también las tasas y las contribuciones especiales, por lo que la calificación de directos e indirectos sólo es correcta en el caso de los impuestos. Véase: «Los impuestos potestativos en la nueva Ley de Haciendas Locales: notas críticas», La Ley, n. $2.269,11$ de julio de 1989, p. 2.

8 Véase, en este sentido: J. J. Ferreiro LaPatza, Curso de Derecho Financiero Español, Ed. Marcial Pons, 16. edición, Madrid, 1994, p. 178; E. Simón AcosTA, E.: Curso de introducción al sistema impositivo estatal, Ed. Ceura, Madrid, 1981, p. 17.

9 En opinión de SAINZ DE BUJANDA, «el análisis jurídico de la distinción, para ser científico, debe marchar por otros derroteros. Jurídicamente, es preferible hablar de «métodos impositivos directos» $\mathrm{y}$ «métodos impositivos indirectos». 
Esto ocurrirá con independencia de la traslación económica del impuesto, la cual podrá tener lugar tanto en los impuestos directos como en los indirectos, dependiendo de la elasticidad-rigidez de la demanda del bien o servicio ${ }^{10}$. La traslación económica del impuesto se efectuará con mayor facilidad cuanto más rígida sea la demanda ${ }^{11}$. Este tipo de repercusión, en palabras de ESEVERRI MARTÍNEZ, se podría denominar repercusión tributaria extra legem ${ }^{12}$. La cual no se debe confundir con la repercusión tributaria secundum legem, de carácter facultativo u obligacional que sería la única que se podría calificar de repercusión tributaria stricto sensu ${ }^{13}$.

\section{B. Impuesto de carácter real}

Esta característica también se señala de forma expresa en el artículo 79.1 LRHL: «El Impuesto sobre Actividades Económicas es un tributo directo de carácter real.» Ello es así puesto que grava una manifestación

\footnotetext{
Se está en presencia de los primeros cuando la norma jurídica tributaria establece la obligación de pago del impuesto a cargo de una determinada persona, sin conceder a ésta un derecho legal a resarcirse, a cargo de otra persona que no forme parte del círculo de obligados en la relación jurídica tributaria, de la suma pagada por la primera al ente público acreedor.
}

Se emplean los segundos cuando la norma jurídica tributaria concede facultades al sujeto pasivo del impuesto para obtener de otra persona, que no forme parte del círculo de obligados en la relación jurídica tributaria, el reembolso del impuesto pagado al ente público acreedor.

De esta manera, la exacción se produce en forma directa cuando el ente público obtiene las cuotas impositivas de aquellas personas a las que la ley quiere efectivamente someter a gravamen; la exacción se produce, en cambio, en forma indirecta cuando el ente público obtiene las cuotas impositivas de personas distintas de aquellas a las que la ley quiere gravar, haciendo que los contribuyentes exijan a estas últimas el reintegro de las cuotas satisfechas por ellos al fiscon. Véase: Lecciones de Derecho Financiero, Servicio de Publicaciones de la Facultad de Derecho de la Universidad Complutense, 10. ${ }^{a}$ edición, Madrid, 1993, p. 177. Véase también: «Impuestos directos e indirectos. Análisis de una vieja distinción», en Hacienda y Derecho, vol. II, IEP, Madrid, 1962, pp. 429 y ss.

10 G. CASADO Ollero, «El principio de capacidad económica y el control constitucional de la imposición indirecta», en Civitas REDF, n. ${ }^{\circ} 32,1981$, p. 548.

$"$ J. M. GarCía-Agúndez Jiménez, «El nuevo Impuesto Municipal sobre Actividades Económicas», en Impuestos, n. ${ }^{\circ} 12,1988$, pp. 50-52.

12 E. ESEVERRI MARTINEZ, Las actuaciones tributarias reclamables en vía económico-administrati$v a$, Ed. Civitas, Madrid, 1983, pp. 80-81.

13 Con relación a los dos criterios que acabamos de comentar, para la distinción entre impuestos directos e indirectos, resulta, a nuestro juicio, más acertado el primero de ellos -esto es, el que considera impuestos directos los que recaen sobre la obtención de ingresos y la titularidad de un patrimonio, e indirectos los que recaen sobre el tráfico patrimonial-, puesto que el segundo criterio quiebra en el caso del Impuesto sobre Transmisiones Patrimoniales y Actos Jurídicos Documentados. 
de riqueza que puede ser pensada sin ponerla en relación con una determinada persona ${ }^{14}$. En el IAE el elemento material del hecho imponible es constitutivamente autónomo. Al gravar el mero ejercicio de una actividad económica es irrelevante quién sea el titular de la misma.

\section{Impuesto objetivo}

Según MARTíN QUERALT y LOZANO SERRANO, estaremos en presencia de impuestos objetivos cuando «las circunstancias personales del obligado al pago no son tomadas en consideración en el momento de cuantificar el importe de su deuda» ${ }^{15}$. De este modo, el IAE constituye un impuesto objetivo puesto que en su cuantificación únicamente se tienen en cuenta circunstancias objetivas que concurran en la actividad económica, y no las circunstancias personales del sujeto pasivo. Aunque se tengan en cuenta algunas situaciones, como el año de inicio de la actividad para practicar bonificaciones, no se trataría en ningún caso de circunstancias personales.

\section{Impuesto periódico}

Son impuestos periódicos aquellos cuyo presupuesto de hecho es una situación o un estado que se prolonga indefinidamente en el tiempo ${ }^{16}$. Teniendo en cuenta que el hecho imponible del IAE, el mero ejercicio de las actividades económicas, es susceptible de prolongarse en el tiempo de forma indefinida, habrá que fraccionar este hecho imponible en diferentes períodos impositivos que en el IAE serán como regla general el año natural, produciéndose el devengo el primer día del período impositivo ${ }^{17}$.

Aunque en el artículo 90.3 LRHL se establezca, para los espectáculos en los que las cuotas estén establecidas por actuaciones aisladas, un devengo instantáneo, esta disposición ha quedado vacía de contenido puesto que las Tarifas del impuesto no han fijado las cuotas correspondientes

\footnotetext{
14 J. J. Ferreiro Lapatza, Curso de Derecho Financiero Español, ob. cit., pp. 179-181.

15 J. Martin Queralt y C. Lozano Serrano, Curso de Derecho Financiero y Tributario, Ed. Tecnos, Madrid, 1991, p. 129.

16 J. J. Ferreiro Lapatza, Curso de Derecho Financiero Español, ob. cit., p. 181.

17 Véanse los apartados 1 y 2 del artículo 90 de la LRHL.
} 
en función de actuaciones aisladas, sino en función de las celebradas a lo largo del período impositivo ${ }^{18}$.

\section{E. Impuesto de titularidad municipal}

A través del artículo 60 de la LRHL se pone de manifiesto que el IAE es un impuesto de carácter municipal ${ }^{19}$. Esto hará que sea el Municipio el sujeto activo de la relación jurídico tributaria, siendo, por tanto, el único que se podría dirigir contra el sujeto pasivo para el cobro del tributo.

Habrá que tener en cuenta que lo anterior no impide que las competencias de gestión recaudatoria puedan delegarse en otras entidades públicas, bien de carácter local, Comunidades Autónomas o incluso la propia Administración del Estado, en cuyo caso seguirá siendo el Municipio el titular del tributo y el sujeto activo del mismo ${ }^{20}$. Incluso en los casos en que se tribute por cuota provincial o nacional ocurrirá lo mismo, puesto que la exacción de dichas cuotas le corresponde a la Administración Tributaria del Estado, que con posterioridad distribuirá su importe entre los Municipios ${ }^{21}$.

\section{F. Impuesto de exigencia obligatoria}

El artículo 60 de la LRHL clasifica los impuestos municipales en impuestos de exigencia obligatoria e impuestos de carácter potestativo, formando parte de los primeros: el Impuesto sobre Bienes Inmuebles, el Impuesto sobre Actividades Económicas y el Impuesto sobre Vehículos de Tracción Mecánica. Mientras que se consideran como impuestos de carácter potestativo: el Impuesto sobre Construcciones, Instalaciones y Obras, y el Impuesto sobre el Incremento del Valor de los Terrenos de

\footnotetext{
18 Véase, en este sentido: J. I. RUBIO DE URQUtA, El Impuesto sobre Actividades Económicas, ob. cit., p. 87; PAGĖs I Galtés, J.: «El Impuesto sobre Actividades Económicas», en J. J. Ferreiro LA. PATZA y otros: Tratado de Derecho Financiero y Tributario Local, Ed. Marcial Pons, Madrid, 1993, p. 759.

19 El artículo 60 de la LRHL dispone: «1. Los Ayuntamientos exigirán, de acuerdo con la presente ley y con las disposiciones que la desarrollan, los siguientes impuestos: a) Impuesto sobre Bienes Inmuebles. b) Impuesto sobre Actividades Económicas. c) Impuesto sobre Vehículos de Tracción Mecánica.»)

20 Véanse artículo 7 y Disposición Transitoria 11 de la LRHL.

21 J. I. RuBio de UrQuí, El Impuesto sobre Actividades Económicas, ob. cit., p. 53.
} 
Naturaleza Urbana, a los que podríamos añadir el Impuesto sobre los Cotos de Caza y Pesca (Impuesto sobre Gastos Suntuarios).

Todos los Municipios españoles están obligados a exigir el IAE, para lo cual no es necesario, por parte de los mismos, la adopción del acuerdo de imposición ni la aprobación de la correspondiente Ordenanza Fiscal, que sólo serán necesarios cuando los Municipios quieran hacer uso de las facultades que ostentan en la cuantificación del impuesto, a través de los coeficientes municipales de población y de situación.

Por otra parte, es importante resaltar que, aunque el impuesto tiene carácter obligatorio, el recargo provincial que se aplica sobre el mismo, y que se regula en el artículo 124 de la LRHL, tiene un carácter opcional.

\section{G. Impuesto censal}

De entre las características que configuran la naturaleza jurídica del IAE, no cabe duda de que es su carácter censal el que mayor polémica doctrinal presenta, al no encontrar justificación la creación de un impuesto con finalidad censal, cuando existen en nuestra normativa vigente otros instrumentos que pueden cumplir esa función censal o de control, entre los que podemos citar: las declaraciones censales derivadas del Real Decreto 1041/1990, el Índice de Entidades del Impuesto sobre Sociedades o el Número de Identificación Fiscal (NIF) ${ }^{22}$.

A nuestro juicio, el IAE puede desempeñar una función censal muy importante, lo cual no quiere decir que se haya creado con esa finalidad principal, pues queda fuera de toda duda que la implantación del IAE tiene como objetivo prioritario ser una importante fuente de ingresos para los Municipios y Provincias. Pero una vez creado el impuesto, no debemos olvidarnos de la utilidad que su carácter censal puede proporcionar a la Administración Tributaria estatal, fundamentalmente de cara a otros impuestos (IRPF, IS, IVA, etc.), sin olvidar otros ámbitos en los que también puede ser útil, como puede ser el caso, entre otros, de la Seguridad Social. Esta función censal tendría mayor operatividad si no quedasen al margen del impuesto ciertas actividades económicas, como las activida-

\footnotetext{
${ }^{22}$ En este sentido, García LuIS señala: «Por lo que dificilmente puede defenderse actualmente la justificación del IAE bajo el argumento del servicio que presta a los fines informativos, aparte de que ciertamente resulta también dificil admitir la creación de un impuesto con esta exclusiva finalidad. En suma, no apreciamos otra motivación en la creación (o mejor, mantenimiento) del IAE que la estrictamente recaudatoria, faceta, por ende, que resulta muy potenciada si se compara con la situación anterion». Véase: «Impuesto sobre Actividades Económicas», ob. cit., p. 450.
} 
des agrícolas, ganaderas dependientes, forestales y pesqueras, exclusión que, creemos, no ha sido un acierto por parte del legislador. Y ello, sin olvidarnos de las exenciones por cuota cero previstas en la Regla $15 .^{\mathrm{a}} \mathrm{de}$ la Instrucción, al disponer: «En estos casos, los sujetos pasivos tampoco estarán obligados a formular declaración alguna.»

\section{H. Impuesto de gestión compartida}

El IAE presenta una gestión compartida entre el Estado y los Municipios, tal y como se desprende del artículo 92 de la LRHL. El Estado es titular de las competencias para la gestión censal del Impuesto (art. 92.1 LRHL) y la gestión inspectora (art. 92.3 LRHL). En el caso de las actividades que tributen por cuota provincial o nacional, todos los aspectos de la gestión corresponderán a la Administración estatal, tal y como se desprende del artículo 86.3 LRHL ${ }^{23}$. Por lo que respecta a los Municipios, en las actividades que tributen por cuota municipal, éstos serán titulares de todas las competencias de gestión, excepto las que correspondan a la gestión censal y gestión inspectora, pudiendo citar, entre otras: gestión liquidatoria, gestión recaudatoria, gestión revisora, gestión en materia de beneficios fiscales y devolución de ingresos indebidos.

Habría que destacar, también, que en la revisión de los actos administrativos dictados por la Administración Tributaria estatal en el ejercicio de sus competencias de gestión, la impugnación de los mismos se podrá realizar ante los Tribunales Económico-Administrativos.

La normativa básica en materia de gestión del IAE está constituida por los artículos 91 y 92 de la LRHL y sus Disposiciones Transitorias $3 .^{\mathrm{a}}$ y 11. ${ }^{a}$ En el ámbito reglamentario destaca el Real Decreto 243/1995, de 17 de febrero, por el que se dictan normas para la gestión del IAE y se regula la delegación de competencias en materia de gestión censal de dicho impuesto ${ }^{24}$.

${ }^{23}$ El artículo 86.3 de la LRHL dispone: «No obstante lo dispuesto en el artículo 92.2 de la presente Ley, la gestión tributaria de las cuotas provinciales y nacionales que fijen las Tarifas del impuesto corresponderán a la Administración Tributaria del Estado, sin perjuicio de las fórmulas de colaboración que, en relación a tal gestión, puedan establecerse con otras entidades. Sobre las referidas cuotas provinciales y nacionales no podrán establecerse el coeficiente ni el índice de situación, ni el recargo provincial, regulados en los artículos 88,89 y 124 de la Ley, respectivamente».

${ }^{24}$ El Real Decreto 243/1995, de 17 de febrero, por el que se dictan normas para la gestión del Impuesto sobre Actividades Económicas y se regula la delegación de competencias en materia de gestión censal de dicho impuesto, viene a sustituir al anterior Reglamento de gestión del IAE, esto es, al Real Decreto 1.172/1991, de 26 de julio. 


\section{EL OBJETO IMPONIBLE EN EL IAE}

Según AlBIÑANA, «el objeto imponible es la definición legal de la capacidad económica a gravar, y de aquí que deba estar presente en su ley reguladora si la capacidad económica, como parece obvio, es nervio y aliento del impuesto justo» ${ }^{25}$. Sin embargo, en la LRHL no se hace mención del objeto imponible del IAE, aunque el mismo pueda ser deducido en función de la regulación general del impuesto y, de forma especial, del precepto que define formalmente el hecho imponible (art. 79) y de la base cuarta del artículo 86.1 de la LRHL.

Consideramos que, aunque el IAE se exija por el mero ejercicio de una actividad económica, recae sobre el rendimiento que se obtiene de la mis$\mathrm{ma}^{26}$. En este sentido, se manifiesta GARCíA LUIS cuando señala: «En suma, no es el ejercicio de una actividad, sino el resultado que se obtiene con el mismo lo que se somete a gravamen, el objeto imponible». El artículo 79 de la LRHL considera el hecho imponible del IAE el mero ejercicio en territorio nacional de actividades empresariales, profesionales y artísticas. Sin embargo, el ejercicio de una actividad económica no constituye un indicador de capacidad económica [recordamos que los indicadores de capacidad económica, según se desprende del artículo 26.1.c) de la Ley General Tributaria, son: la obtención de ingresos, la titularidad de

Con posterioridad, primero a través del apartado 2 de la Disposición Adicional 19. ${ }^{a}$ de la Ley 18/1991, de 6 de junio, del IRPF, y después por medio del artículo 78.3 de la Ley $31 / 1991$, de 30 de diciembre, de Presupuestos Generales del Estado para 1992, se dio nueva y sucesiva redacción al artículo 92.3 de la LRHL, para posibilitar a los Municipios, Diputaciones Provinciales, Cabildos y Consejos Insulares y Comunidades Autónomas, asumir por delegación las competencias en materia de inspección del IAE.

Una modificación de enorme trascendencia en cuanto a la gestión del LAE — puesto que otorga una mayor participación a los Municipios y a otras entidades públicas en la gestión integral de dicho impuesto- tuvo lugar por medio del párrafo sexto del apartado 1 del artículo 8 de la Ley 22/1993, de 29 de diciembre, al dar nueva redacción al artículo 92 de la LRHL, con la casi única finalidad de permitir a los Municipios, Diputaciones Provinciales, Cabildos y Consejos Insulares y Comunidades Autónomas asumir por delegación las competencias en materia de gestión censal de las cuotas municipales del IAE.

Esta sustancial alteración del régimen de gestión censal del IAE ha provocado la aparición del nuevo Reglamento de Gestión del IAE, es decir, del Real Decreto 243/1995, de 17 de febrero, que lleva a cabo una reordenación íntegra de dicho régimen reglamentario, junto con la regulación del régimen de delegación de competencias en materia de gestión censal del impuesto.

${ }^{25}$ C. Albiñana Garcta-Quintana, Sistema Tributario Español y Comparado, Ed. Tecnos, Madrid, 1992, p. 76.

${ }^{26}$ Se ha entendido tradicionalmente por objeto imponible el indicador de capacidad económica que se somete a gravamen (obtención de ingresos, titularidad de un patrimonio y tráfico patrimonial). En la terminología utilizada por FerREIRo sería equivalente al objeto-fin del tributo. Véase: J. J. Ferreiro lapatza, Curso de Derecho Financiero Español, ob. cit., pp. 356-361. 
un patrimonio y el tráfico patrimonial]. De este modo, se ha considerado el ejercicio de una actividad económica como presupuesto necesario para la obtención de los ingresos, de tal forma que en vez de llevar a la sede del hecho imponible el resultado del ejercicio, se ha estimado más conveniente tipificar el instrumento. En esta opción han pesado, por un lado, razones históricas ya que esta situación se producía en las anteriores Licencias Fiscales y, por otro, el intento de no exteriorizar de forma clara la doble imposición interna que genera este impuesto, sin olvidar tampoco el deseo de hacer creer a los Municipios que cuentan con un nuevo impuesto, diferente a los que existen en el ámbito estatal ${ }^{27}$.

La base cuarta del artículo 86.1 de la LRHL establece que «las cuotas resultantes de la aplicación de las Tarifas no podrán exceder del 15 por 100 del beneficio medio presunto de la actividad gravada» ${ }^{28}$.

Sin embargo, el hecho de exigirse el IAE, aun en los casos en que no se obtenga ningún beneficio en el ejercicio de la actividad, ha originado que parte de la doctrina considere como objeto imponible de este impuesto, el propio ejercicio de la actividad. Así se manifiesta RUBIO DE URQUÍA, al se-

27 T. Garcla LuIs, «Impuesto sobre Actividades Económicas», ob. cit., pp. 450-451.

${ }^{28}$ Respecto a la Licencia Fiscal de Actividades Comerciales e Industriales, el artículo 284.6 del Real Decreto Legislativo 781/1986, de 18 de abril, establecía que «las cuotas tributarias resultantes de aplicar las tarifas no deberán exceder del 15 por 100 del beneficio medio presunto de la actividad gravada, pero sin que, en ningún caso, sean inferiores a la cantidad de 3.960 pesetas anuales por actividad».

Por su parte, el artículo 309.b) del citado texto normativo, en cuanto a la Licencia Fiscal de Actividades Profesionales y Artísticas disponia: «Las cuotas serán determinadas en función del rendimiento económico medio de cada actividad profesional, sin que en ningún caso sean inferiores a las 6.600 ptas.».

La mayoría de la doctrina consideraba que el objeto imponible de las anteriores Licencias Fiscales estaba constituido por el rendimiento que se obtenía del ejercicio de las correspondientes actividades. Así, podemos citar, entre otros:

- F. Poveda Blanco, «Licencia Fiscal de Actividades Comerciales e Industriales: criterios y técnicas de valoración", en Crónica Tributaria, n. ${ }^{\circ} 46,1983$, p. 121. Para este autor, la Licencia Fiscal «tiene como objeto imponible los rendimientos medios, ya que no los efectivos, que la ley en acto de presunción -iuris et de iure - entiende obtenidos por el ejercicio de una serie de actividades empresariales especificas, así como de aquellos otras que, aun no figurando en las Tarifas de este Impuesto, sean declaradas análogas a las mismas».

- R. Drake Drake, «Licencia Fiscal del Impuesto Industrial», en Revista de Derecho Financiero y Hacienda Püblica, n. ${ }^{\circ}$ 67, p. 407.

- C. Albiñana Garcia-Quintana, Sistema Tributario Español y Comparado, Ed. Tecnos, Madrid, 1986, p. 641 .

- J. L. MUÑoz DEL CASTILLO, «Licencia Fiscal del Impuesto Industrial y Ley de Hidrocarburos», en Crónica Tributaria, n. ${ }^{\circ} 14,1975$, p. 87. 
ñalar que «es, en efecto, la existencia de una actividad económica lo que pone de manifiesto la capacidad económica del contribuyente, y no el hecho de que a través del ejercicio de aquélla se obtenga o no beneficios» ${ }^{29}$.

Para PAGÈs I GALtÉs, «sin duda alguna es el beneficio susceptible de generar la actividad lo que pretende gravar el legislador, el objeto-fin del IAE. Pero, al no coincidir el objeto-fin con el objeto-material, el gravamen se exige se produzca o no dicho beneficio, bastando el mero ejercicio de la actividad para que se devengue el tributo» ${ }^{30}$.

Aunque de hecho sea así, como también lo ha puesto de manifiesto la propia Dirección General de Coordinación con las Haciendas Territoriales (DGCHT), no se puede considerar como objeto imponible del IAE el ejercicio de las actividades económicas ${ }^{31}$. El hecho de que el IAE grave en la práctica una actividad económica que no obtenga ningún beneficio constituye un gravísimo atentado al principio de capacidad económica, que debería provocar, a nuestro juicio, la inconstitucionalidad del impuesto en este aspecto. Jamás el ejercicio de una actividad económica se podrá considerar como indicador de capacidad económica, considerándose solamente como tal la obtención de ingresos que deriven de la misma ${ }^{32}$. De esta forma, el IAE, si no quiere incurrir en inconstitucionalidad, únicamente podrá gravar aquellas actividades económicas que obtengan ingresos ${ }^{33}$.

\footnotetext{
29 J. I. RUBIO DE URQUí, El Impuesto sobre Actividades Económicas, ob. cit., p. 63.

30 J. PaGés I Galtés, «El Impuesto sobre Actividades Económicas», ob. cit., p. 768.
}

31 Véase la contestación de la DGCHT de 14 de mayo de 1992 a una consulta efectuada por una asociación sin ánimo de lucro, en la que se dispone que «el hecho imponible del impuesto se realiza en el ejercicio de la actividad, con independencia de que exista o no ánimo de lucro. Se trata, pues, de un impuesto que grava el mero ejercicio, y ello en orden a la materialización de su función censal».

32 Aunque se esfuerce en lo contrario la Memoria que acompaña al Proyecto de la Ley Reguladora de las Haciendas Locales, cuando señala que para el IAE «el mero ejercicio de actividades económicas revela la capacidad contributiva de las personas obligadas a satisfacerlo». Véase: Memoria en Secretaría General del Congreso de los Diputados: «Haciendas Locales (Documentación preparada para la tramitación del Proyecto de Ley Reguladora de las Haciendas Locales)», en Documentación, n. ${ }^{\circ} 70,1988$, p. 1788.

${ }^{33}$ Por consiguiente, no nos parece acertada la conclusión a que llega la STSJ de Valencia de 10 de noviembre de 1994 (Jurisprudencia Tributaria 1441), al sostener que el IAE no vulnera el principio de capacidad económica. En su Fundamento Jurídico $5 .^{\circ}$ señala: «En consecuencia, estaremos ante un impuesto de nueva factura que, en el presente supuesto, grava una actividad comercial en base a estimaciones objetivas sobre el presunto rendimiento de dicha actividad, en lógica coherencia con los antecedentes históricos y con el sistema tributario español, respetando el principio de capacidad económica del artículo $31.1 \mathrm{CE}(. .$.$) . No existe prueba o indicio alguno de que el IAE no$ respete los principios de capacidad económica, justicia o progresividad.»

En similares términos se pronuncia la STSJ de Galicia de 16 de noviembre de 1991 (Quincena Fiscal, n. $\left.{ }^{\circ} 2,1995\right)$. 
Para que la obtención de ingresos constituya un indicador de capacidad económica ha de tratarse de ingresos ciertos y no de ingresos presuntos o ficticios ${ }^{34}$.

Una posibilidad que señala GARCíA LUIS consistiría en aceptar el gravamen de beneficios presuntos si el mismo se estableciera con carácter «inicial», articulándose de forma paralela un mecanismo de ajuste en función de los rendimientos efectivamente obtenidos, y que llevara consigo, o bien un ingreso adicional o una reducción del impuesto satisfecho con anterioridad ${ }^{35}$. Sin embargo, no se establece ningún mecanismo de ajuste, a diferencia de lo que ocurre en Italia con el Impuesto municipal sobre el ejercicio de empresas, artes y profesiones ${ }^{36}$. De este modo, tienen lugar supuestos de tributación de sujetos que obtienen beneficios por debajo de la media o incluso que incurren en pérdidas.

Aunque esta situación ya se producía con las anteriores Licencias Fiscales, existe una sustancial diferencia, puesto que las cuotas de éstas eran mucho más reducidas, teniendo, al igual que en el IAE, el carácter de gasto deducible en el IRPF y en el IS. En cambio, con la actual normativa del IAE la situación es muy diferente, dado el alto potencial recaudatorio con el que la LRHL configura dicho impuesto.

En suma, consideramos que el objeto imponible del Impuesto sobre Actividades Económicas sólo lo puede constituir los ingresos que se ob-

${ }^{34}$ F. MoschetTI, El principio de capacidad contributiva, IEF, Madrid, 1980, p. 303.

CHECA GONZÁLEZ señala que «el gravar, por otra parte, beneficios presuntos supone un claro atentado al principio constitucional de capacidad económica, el cual, rectamente entendido, exige que tributen sólo manifestaciones económicas reales y no ficticias.

(...) Ello implica un desconocimiento de la esencia del principio de capacidad económica, ya que el mismo, como bien ha señalado CASADo OLLERo, «exige que dicha capacidad, además de presupuesto legitimador del tributo, sea también presupuesto legitimador de cada concreto acto de imposición, de tal suerte que si así no se hiciese se estaría atentando contra la justicia tributaria, que no puede entenderse cumplida aludiendo a que en la "normalidad de los casos" los efectos negativos y contrarios a la Constitución no se producirian - en este supuesto alegando que en la generalidad de ellos los beneficios particulares van a encontrarse situados dentro de esa cifra del 15 por $100-$, ya que, como afirma CASADO OLLERO, dicho criterio "no puede esgrimirse con éxito para ignorar aquellas situaciones particulares en las que, justamente, la tutela constitucional debe mostrarse especialmente operativa"».

Véase: C. CheCA GonzÁleZ, «El Impuesto sobre Actividades Económicas», en Impuestos, n. ${ }^{\circ} 23$, 1989, p. 28.

${ }^{35}$ T. GaRCla LuIs, «Impuesto sobre Actividades Económicas», ob. cit., pp. 452-453.

36 Véase el Decreto Ley que crea el Impuesto municipal sobre el ejercicio de empresas, artes y profesiones, de 2 de marzo de 1989, número 66, convertido con modificaciones en la Ley de 24 de abril de 1989 , número 144. 
tienen en el ejercicio de una actividad económica, por lo que, en los casos en que no existiesen estos ingresos, el impuesto incurrirá en inconstitucionalidad al no gravar ningún indicador de capacidad económica. En consecuencia, sería necesario establecer mecanismos de devolución de lo pagado en los supuestos en que no existiesen ingresos, para que el impuesto no vulnerase el principio de capacidad económica.

Por otra parte, la cuantificación del impuesto tendría que determinarse en función de los ingresos obtenidos y no de una serie de «signos externos» al resultado de la actividad que, de ningún modo, nos permiten conocer con certeza si la actividad ha generado o no beneficios, y en el caso positivo la cuantía de los mismos ${ }^{37}$.

\section{EL HECHO IMPONIBLE DEL IAE}

\section{Definición del hecho imponible}

El hecho imponible del Impuesto sobre Actividades Económicas se define en el artículo 79.1 de la LRHL, y está constituido por «el mero ejercicio en territorio nacional de actividades empresariales, profesionales o artísticas, se ejerzan o no en local determinado y se hallen o no especificadas en las tarifas del impuesto».

Siguiendo a RUBIO DE URQUía, la mera lectura de esta definición legal nos traslada a la idea que, desde siempre - y de forma incorrecta-, ha tenido el contribuyente acerca de las Licencias Fiscales, al considerarlas como auténticas autorizaciones administrativas para el ejercicio de las actividades económicas. Además, se pone de manifiesto todo el primitivismo, tosquedad e irracionalidad intrínseca que el IAE hereda de las anteriores Licencias Fiscales ${ }^{38}$.

La sujeción al IAE tiene lugar aunque no se lleve a cabo el ejercicio de la actividad en un local, quedando gravadas, de este modo, todas aquellas actividades que no se realizan en un local, como ocurre con el comercio

\footnotetext{
${ }^{37}$ Como ha señalado CHECA GonZÁLEZ, «proceder de este modo, esto es, haciendo abstracción de parámetros fiables de capacidad económica, como serían, por ejemplo, volumen de ingresos, número de empleados, elementos del activo inmovilizado, etc., y no estableciéndose ratio alguna entre resultados e inversiones para determinar la rentabilidad, implica algo tan contrario a la justicia tributaria como el establecimiento de la presunción de que si alguien decide iniciar una actividad conociendo previamente la cuota que ha de pagar, es que está reconociendo que puede pagarla». Véase: «El Impuesto sobre Actividades Económicas», ob. cit., p. 28.
}

38 J. I. RUBIO DE URQUí, El Impuesto sobre Actividades Económicas, ob. cit., pp. 60-61. 
ambulante o el que se lleva a cabo por correo o catálogo ${ }^{39}$. Sin embargo, el que la existencia o inexistencia de un local sea indiferente para la sujeción de una actividad el IAE no lo es para la cuantificación del mismo, ya que únicamente el titular de una actividad que la ejerza en un local tributará por el módulo indiciario superficie, además de la aplicación del coeficiente de situación. Dicha circunstancia puede ser generadora de injusticias, como así ha sido puesto de manifiesto por la doctrina ${ }^{40}$.

También resulta irrelevante para la sujeción de una actividad económica al IAE el que ésta se encuentre o no especificada en las Tarifas del impuesto. El artículo 80 apartado 2 establece que «el contenido de las actividades gravadas se definirá en las Tarifas del Impuesto», entendiendo por "contenido de las actividades» el conjunto de operaciones o labores propias de cada una de ellas.

La función censal que debe desempeñar el IAE exige que las distintas actividades económicas (empresariales, profesionales y artísticas) estén debidamente especificadas en las Tarifas del impuesto. No obstante, se considera imposible la especificación de todas las actividades existentes o que puedan surgir en el futuro, lo cual hace que el impuesto no se limite a gravar las actividades especificadas en las Tarifas, sino que somete a tributación cualquier actividad económica con independencia de que se encuentre o no especificada en las mismas.

Creemos que, dada la enorme especificación que existe en las actuales Tarifas del IAE, las actividades que no vengan expresamente recogidas en las mismas tendrán que constituir necesariamente un número reducido. En concreto, en la Sección 1. ${ }^{\mathrm{a}}$, que se refiere a las actividades empresariales - sector éste que, sin duda, puede generar el mayor número de problemas en cuanto a la adecuada ubicación de las mismas- se recogen más de 800 actividades.

${ }^{39}$ E. MARTINEZ RoBles propuso en los trabajos preparatorios del IAE que la utilización de los locales debería ser necesaria para el hecho imponible del futuro impuesto ante la necesidad de integrar en el nuevo tributo al Impuesto sobre la Radicación, además de ser conveniente la delimitación territorial del hecho imponible para poder compatibilizar el impuesto con el principio de autonomía local. Véase AA.VV.: Las Finanzas municipales en el Estado de las Autonomias. Estudios y propuestas. Diputación de Barcelona, 1985, pp. 133-134.

${ }^{40}$ En este sentido, CHECA González ha señalado que «esta circunstancia actúa en detrimento de los empresarios y profesionales establecidos, que lógicamente son la mayoría, frente a los que no lo están; ya que mientras aquéllos pueden llegar a verse gravados por la ubicación de su local, como después veremos, no sucede así, sin embargo, respecto a estos últimos, para los cuales, como ya se señaló, el único posible incremento sobre las cuotas mínimas a satisfacer va a venir sólo de la aplicación de los coeficientes que los Ayuntamientos pueden establecer con arreglo a su respectiva población, aplicable también a aquéllos». Véase: «El Impuesto sobre Actividades Económicas», ob. cit., p. 13. 
Por otra parte, la inclusión de nuevas actividades en las Tarifas se puede llevar a cabo por medio de las anuales Leyes de Presupuestos Generales del Estado, tal y como establece el artículo 87.1 de la LRHL: «Las Leyes de Presupuestos Generales del Estado podrán modificar las Tarifas del Impuesto, así como la Instrucción para la aplicación de las mismas, y actualizar las cuotas en ellas contenidas» ${ }^{41}$.

El artículo 79.1 de la LRHL dispone, como hemos comentado, que el hecho imponible del IAE está constituido por «el mero ejercicio en territorio nacional de actividades empresariales, profesionales o artísticas»» ${ }^{42}$. Como ha puesto de manifiesto RUBIO DE URQUíA, por medio de esta formulación el legislador ha pretendido, de modo innecesario, poner de manifiesto las dos situaciones siguientes:

a) Que el IAE no sujeta a gravamen el ejercicio en el extranjero de actividades económicas por parte de residentes en España.

b) Que el IAE somete a gravamen el ejercicio en España de actividades económicas por parte de no residentes ${ }^{43}$.

Si tenemos en cuenta que no es necesaria la especificación de las actividades económicas en las Tarifas del IAE, ni la existencia de un local donde se realice su ejercicio, la clave de bóveda del impuesto se centra en el mero ejercicio de las actividades empresariales, profesionales o artísticas. Según la Memoria que acompaña al Proyecto de Ley Reguladora de

${ }^{41}$ La actual redacción del artículo 87.1 de la LRHL procede del artículo 26.Tres, del Real Decreto-Ley $12 / 1995$, de 28 de diciembre, sobre medidas urgentes en materia presupuestaria, tributaria y financiera.

42 En contestación de 5 de noviembre de 1991, acerca de una consulta sobre si se encuentra sujeta al IAE la actividad de emisión de una determinada tarjeta de crédito comercial por una Entidad no residente, desde su establecimiento situado fuera del territorio nacional y que va a ser utilizada en España por transportistas extranjeros, la Dirección General de Coordinación con las Haciendas Territoriales (DGCHT) ha señalado que «el Impuesto sobre Actividades Económicas grava el mero ejercicio en territorio nacional de actividades empresariales, profesionales o artísticas, se ejerzan o no en local determinado y se hallen o no especificadas en las Tarifas del Impuesto, tal y como dispone el artículo 79.1 de la Ley 39/1988, de 28 de diciembre, Reguladora de las Haciendas Locales.

Expuesto lo anterior, la actividad de emisión de una determinada tarjeta de crédito por una entidad no residente desde su establecimiento situado fuera del territorio nacional no constituye el hecho imponible del Impuesto sobre Actividades Económicas, puesto que el lugar de realización de la actividad está situado fuera del territorio nacional y, en consecuencia, dicha actividad no está sujeta al Impuesto».

43 J. I. RUBIo de URQuiA, El Impuesto sobre Actividades Económicas, ob. cit., p. 65. Este autor ha señalado que «la limitación de la efectividad del IAE al "territorio nacional" es una necesidad que, en todo caso, se desprende de los principios inspiradores de los tributos locales, contenidos en el artículo 6 de la LRHL (...), y que tienden a garantizar la territorialidad de dichos tributos». 
las Haciendas Locales, el mero ejercicio de una actividad es el elemento esencial del hecho imponible, «sin que puedan añadírsele a este concepto matizaciones o calificaciones de ningún género, tales como las circunstancias personales del sujeto pasivo, al ánimo o no de lucro en el ejercicio de la actividad, la obtención o no de beneficios para el desarrollo de la misma, la realización de la actividad en un local concreto o no, el carácter habitual o esporádico en su ejercicio, su inclusión expresa o no en las tarifas del impuesto o cualesquiera otras» ${ }^{44}$.

Sin embargo, para GARCía LUIS, no todas estas circunstancias a las que hace mención la Memoria son indiferentes. Si exceptuamos la indiferencia del ejercicio en un local o de la especificación en las Tarifas y de la irrelevancia de las circunstancias personales del sujeto pasivo (lo cual es lógico dada su naturaleza de impuesto de carácter real), a juicio del citado autor, es necesaria, para que se genere el hecho imponible, la habitualidad en el ejercicio de la actividad ${ }^{45}$. RUBIO DE URQUíA, por el contrario, no considera necesaria la habitualidad en el ejercicio de la actividad ${ }^{46}$.

\section{Concepto de actividad económica}

Para el análisis del concepto de actividad económica debemos partir del apartado 1 del artículo 80 de la LRHL, según el cual «se considera que una actividad se ejerce con carácter empresarial, profesional o artístico, cuando suponga la ordenación por cuenta propia de medios de producción y de recursos humanos o de uno de ambos, con la finalidad de intervenir en la producción o distribución de bienes o servicios» ${ }^{47}$. Debemos destacar, siguiendo a CHECA GONZÁLEZ, que el IAE renuncia a fijar criterios propios que definan las actividades empresariales, profesionales o artísticas, puesto que en él se han incorporado las nociones existentes en el ordenamiento tributario estatal ${ }^{48}$. Encontramos una definición si-

44 Secretaria General del Congreso de los Diputados: Haciendas Locales (Documentación preparada para la tramitación del Proyecto de Ley Reguladora de las Haciendas Locales), en Documentación, n. ${ }^{\circ} 70$, junio de 1988, p. 1790.

${ }^{45}$ T. García LuIs, «Impuestos sobre Actividades Económicas», ob. cit., p. 462.

46 J. I. Rubio de Urquía, El Impuesto sobre Actividades Económicas, ob. cit., p. 62.

47 En igual sentido, se pronuncia el apartado 1 de la Regla 3. a de la Instrucción del IAE al señalar: «Tienen la consideración de actividades económicas, cualesquiera actividades de carácter empresarial, profesional o artístico. A estos efectos se considera que una actividad se ejerce con carácter empresarial, profesional o artístico, cuando suponga la ordenación por cuenta propia de medios de producción y de recursos humanos, o de uno de ambos, con la finalidad de intervenir en la producción o distribución de bienes o servicios.»

48 C. CheCA González, «El Impuesto sobre Actividades Económicas», ob. cit., p. 14. 
milar en el artículo 40.Uno de la Ley 18/1991, del Impuesto sobre la Renta de las Personas Físicas, en el párrafo primero del artículo 134.3 de la Ley 43/1995, de 27 de diciembre, del Impuesto sobre Sociedades, y en el artículo 5.Dos de la Ley 37/1992, del Impuesto sobre el Valor Añadido ${ }^{49}$.

En definitiva, y a efectos del IAE, tienen la consideración de actividades empresariales, profesionales o artísticas las que supongan la ordenación por cuenta propia de los factores de producción (capital y trabajo) o de uno de ambos, con la finalidad de producir bienes y servicios para el mercado, se ejerzan o no con carácter habitual, se persiga o no fin de lucro, y con independencia de que se obtengan o no beneficios mediante el desarrollo de las mismas.

Merece destacarse de la definición del hecho imponible del IAE, que en su seno se contempla el gravamen conjunto de las actividades empresariales, profesionales y artísticas. Lo anterior constituye una novedad, como así lo ha puesto de manifiesto MARTín QUERALT, al señalar que «la definición del hecho imponible del tributo se mantiene prácticamente igual a la de los impuestos que sustituye. Aunque incluyendo en el mismo concepto el ejercicio de actividades profesionales y artísticas, por un lado, y empresariales, por otro» ${ }^{50}$.

Por otra parte, el gravar de forma conjunta estas actividades no constituye una novedad en nuestro Derecho, puesto que ya se hizo en el ámbito del Impuesto sobre la Renta de las Personas Físicas. El motivo quizá tenga su fundamento en que actualmente el factor de producción constituido

49 El artículo 40.Uno de la Ley 18/1991 del IRPF dispone: «Se considerarán rendimientos integros de actividades empresariales o profesionales aquellos que, procediendo del trabajo personal y del capital conjuntamente, $o$ de uno solo de estos factores, supongan por parte del sujeto pasivo la ordenación por cuenta propia de medios de producción y de recursos humanos o de uno de ambos, con la finalidad de intervenir en la producción o distribución de bienes o servicios.»

El párrafo primero del artículo 134.3 de la Ley 43/1995, de 27 de diciembre, del Impuesto sobre Sociedades, dispone: «Se considerarán rendimientos de una explotación económica todos aquellos que procediendo del trabajo personal y del capital conjuntamente, o de uno solo de estos factores, supongan por parte del sujeto pasivo la ordenación por cuenta propia de los medios de producción y de recursos humanos o de uno de ambos con la finalidad de intervenir en la producción o distribución de bienes o servicios.»

Por su parte, el artículo 5.Dos de la Ley 37/1992, de la Ley del Impuesto sobre el Valor Añadido, establece que «son actividades empresariales o profesionales las que impliquen la ordenación por cuenta propia de factores de producción materiales y humanos o de uno de ellos, con la finalidad de intervenir en la producción o distribución de bienes o servicios».

so J. J. Ferreiro Lapatza, E. Simón Acosta y J. Martin Queralt, El Proyecto de Ley Reguladora de las Haciendas Locales, IEF, Madrid, 1988, p. 120. 
por el capital tiene cada vez más importancia frente a situaciones anteriores en las que predominaba el factor trabajo. Esta equiparación entre las actividades empresariales, profesionales y artísticas ha sido bien recibida por la doctrina, como ha puesto de manifiesto LASARTE ÁlVAREZ, para quien «parece acertado que el proceso de simplificación y racionalización normativa haya conducido a idéntico tratamiento de los beneficios empresariales con independencia del carácter de las explotaciones económicas, pues las posibles disparidades no deben establecerse tanto en función de éste como en atención al volumen de operaciones, que influye decisivamente en los modos de gestión empresarial y control fiscal»» ${ }^{51}$.

De este modo, la normativa del IAE define de forma conjunta las actividades empresariales, profesionales y artísticas, en cuanto resulta común a todas ellas la ordenación por cuenta propia de factores de producción con la finalidad de producir bienes o servicios. Como podemos observar, estamos ante una definición que además de proceder de la ciencia económica está muy próxima al concepto de «empresa» que ha elaborado la doctrina mercantilista. Para URÍA se puede calificar como empresa «el ejercicio profesional de una actividad económica planificada, con la finalidad de intermediar en el mercado de bienes o servicios» 52 .

\section{Concepto de actividades empresariales, profesionales y artísticas}

\section{A. Concepto de actividades empresariales}

Según la redacción originaria del artículo 79.2 de la LRHL, se consideraban, a efectos del IAE, actividades empresariales: las agrícolas, ganaderas, forestales, pesqueras, industriales, comerciales, de servicios y mineras. Este precepto fue posteriormente modificado por el artículo 1 de la Ley 6/1991, de 11 de marzo, y que tuvo por finalidad, como ha puesto

51 J. J. Ferreiro Lapatza, J. Lasarte Álvarez, J. Martín Queralt y C. Palao Taboada, Comentarios a la Ley del Impuesto sobre la Renta de las Personas Físicas, Ed. Civitas, Madrid, 1983, p. 156.

52 En este sentido, LaSARTE Álvarez, al comentar el artículo 18 de la Ley del Impuesto sobre la Renta de las Personas Físicas 44/1978, de 8 de septiembre, ha puesto de manifiesto que «en su deseo de caracterizar estas actividades a efectos de su tratamiento fiscal el legislador se ha visto obligado, ante tal ausencia de un concepto jurídico de empresa distinto del económico, a una descripción de las mismas en base a los datos de uordenación por cuenta propia de los medios de producción» y de la «finalidad de intervenir en la producción o distribución de bienes o servicios»»». Véase: J. J. Ferreiro lapatza, J. Lasarte Álvarez, J. Martin Queralt y C. Palao Taboada, Comentarios a la Ley del Impuesto sobre la Renta de las Personas Fisicas, ob. cit., p. 157. 
de manifiesto RUBIO DE URQUÍA, excluir de forma arbitraria del hecho imponible del IAE a las actividades agrícolas, ganaderas dependientes, forestales y pesqueras ${ }^{53}$. De este modo, en la vigente redacción del artículo 79.2 de la LRHL se establece que «se consideran, a los efectos de este impuesto, actividades empresariales las ganaderas, cuando tengan carácter independiente, las mineras, industriales, comerciales y de servicios. No tienen, por consiguiente, tal consideración las actividades agrícolas, las ganaderas dependientes, las forestales y las pesqueras, no constituyendo hecho imponible por el impuesto ninguna de ellas».

No obstante, debemos destacar que ni en la LRHL ni en la Instrucción para la aplicación de las Tarifas se contienen otras normas que permitan una mayor delimitación del concepto de actividades empresariales. Podemos destacar como excepciones a lo anterior: a) el concepto que de las actividades de comercio mayorista se contiene en el párrafo segundo de la Regla 4.2.C de la Instrucción; b) el concepto que de las actividades de comercio minorista se contiene en el párrafo segundo de la Regla 4.⒉D. de la Instrucción.

El contenido de las distintas actividades empresariales se contempla (además de en las notas que existen en las Tarifas) en el régimen de facultades que, para cada sector empresarial, vienen recogidas en la Regla 4. ${ }^{\mathrm{a}}$ de la Instrucción.

Por otro lado, la normativa del IAE no ha procedido a la elaboración de un concepto que permita la distinción de las actividades empresariales, profesionales y artísticas, y que, de este modo, posibilitase la calificación de aquellas actividades que no se encontrasen especificadas en las Tarifas.

En este sentido, y como ha señalado POVEDA BLANCO, resulta evidente que, tanto en la LRHL como en la normativa de desarrollo, se ha incurrido en la grave omisión de no instrumentar los conceptos que permitan diferenciar a estas tres categorías de actividades económicas, perfilando no sólo los caracteres comunes sino, también, las notas diferenciadoras ${ }^{54}$.

\footnotetext{
53 J. I. RUBIO DE URQUiA, El Impuesto sobre Actividades Económicas, ob. cit., p. 66.

${ }^{54}$ F. Poveda Blanco, El Impuesto sobre Actividades Económicas, Ed. Deusto, Bilbao, 1994, p. 40.
}

En este sentido, son significativas las palabras de este autor al respecto: «Éste y no otro es el nudo gordiano de la cuestión. ¿Cómo algo indefinido y no especificado puede servir para definir una actividad económica como empresarial? Dicho de otro modo y siguiendo el procedimiento a que parece conducir la norma, si en una actividad concurren los aspectos legales que nos permitan calificarla como económica es evidente que su realización exigirá el cumplimiento de la obligación de presentar la decla- 
Esta omisión del legislador del IAE a la hora de diferenciar conceptualmente las tres categorías de actividades económicas - empresariales, profesionales y artísticas - se debe, a nuestro juicio, a que tal diferenciación conceptual es materialmente imposible, puesto que la misma no existe.

En este sentido, GARCÍA-OVIES sostiene, con relación a las actividades empresariales y profesionales en el IRPF, que «la diferencia en algunos aspectos de su tratamiento tributario obliga a fijar, aunque sea acudiendo a criterios ficticios, los límites entre ambas actividades, aun cuando previamente nos hayamos ocupado de justificar el porqué de su regulación conjunta. Estamos, pues, ante un contrasentido que obliga a inventar, mejor que a elaborar, una teoría sin fundamento ni suficiente justificación» ${ }^{55}$.

De ahí que Simón ACOSTA haya puesto de manifiesto - también con relación al IRPF - que la mejor solución (de lege ferenda) consista en «eliminar las particularidades del régimen jurídico de la tributación de los rendimientos de profesionales y artistas, consiguiéndose así la plena unificación con las rentas empresariales» ${ }^{56}$.

\section{B. Concepto de actividades profesionales}

A tenor de la Regla 3. 3 de la Instrucción del IAE, «tienen la consideración de actividades profesionales las clasificadas en la Sección $2 .^{\mathrm{a}}$ de las Tarifas, siempre que se ejerzan por personas fisicas. Cuando una persona jurídica o una Entidad de las previstas en el artículo 33 de la Ley General Tributaria, ejerza una actividad clasificada en la Sección $2 .^{a}$ de las Tarifas, deberá matricularse y tributar por la actividad correlativa o análoga de la Sección $1 .^{a}$ de aquéllas».

ración de alta y pagar. Mas procederá conocer bajo qué grupo o epígrafe. Para ello habrá que "rastrear" las Tarifas y, es claro, que si el nombre de la actividad figura en la sección $1 .^{2}$ de las mismas nos encontraremos ante una actividad calificada por la Administración como empresarial; si se halla en la sección $2 .^{a}$ se tratará de una actividad profesional; y si se encuentra en la sección $3 .^{a}$ su calificación apropiada es la de actividad artística. Pero, lejos del ámbito de las actividades especificadas, la situación se torna insoluble, pues si una actividad no se encuentra especificada en las Tarifas y si desconocemos su condición de empresarial, profesional o artística, porque la norma no ha establecido definiciones diferenciadoras, es claro que de nada servirá el criterio citado y que su calificación habrá de realizarse por mera intuición del contribuyente o del funcionario a la hora de practicar el alta.»

55 I. García-Ovies Sarandeses, «Artículo 40 IRPF. Rendimientos íntegros de Actividades Empresariales y Profesionales», en Comentarios a la Ley del Impuesto sobre la Renta de las Personas Fisicas y a la Ley del Impuesto sobre el Patrimonio, Ed. Aranzadi, Pamplona, 1995, p. 657.

${ }^{56}$ E. Simón Acosta, «Artículo 18», en Comentarios a las Leyes Tributarias y Financieras. Impuesto sobre la Renta de las Personas Fisicas, Edersa, Madrid, 1983, p. 194. 
De este modo, y como ha señalado PAGĖS I GALTÉs, la normativa anterior se sirve de dos criterios para delimitar el concepto de actividad profesional, al no establecerse legalmente la definición del mismo. El primer criterio de carácter formal otorga el carácter de actividades profesionales a las clasificadas en la Sección 2. ${ }^{a}$ de las Tarifas. El segundo criterio de carácter subjetivo considera que las actividades profesionales solamente pueden ser ejercidas por personas físicas ${ }^{57}$.

El hecho de que las personas jurídicas o entes del artículo 33 de la Ley General Tributaria no puedan ejercer una actividad profesional constituye una auténtica novedad respecto de la Licencia Fiscal de Actividades Profesionales y Artísticas ${ }^{58}$. En opinión de RUBIO DE URQUíA, «lo que subyace tras esta norma es, en realidad, una clara identificación de la esencia de «lo profesional» con la persona física, evitando, así, que auténticas actividades empresariales puedan adoptar la forma, al menos a efectos del impuesto, de actividades profesionales» ${ }^{59}$.

MENÉNDEZ MORENO da la siguiente definición: «Es profesional quien de forma independiente se dedica a prestar servicios para los que se requiere cualificación intelectual o técnica, con posibilidad de obtener la pertinente contraprestación» ${ }^{60}$. No obstante, este concepto habrá de ser completado en función de una serie de consideraciones en función del sujeto, el objeto y la forma de prestación de los servicios profesionales.

57 J. Pagès I Galtês, «El Impuesto sobre Actividades Económicas», ob. cit., p. 777.

58 El artículo 301 del Real Decreto Legislativo 781/1986 de 18 de abril, al regular los sujetos pasivos de la Licencia Fiscal de Actividades Profesionales y Artísticas disponía que «serán sujetos pasivos del impuest $\mathrm{J}$ todas las personas físicas y jurídicas, así españolas como extranjeras, que realicen en territorio español cualquiera de las actividades que originan el hecho imponible.

Igualmente tendrán la condición de sujetos pasivos en esta forma del impuesto las herencias yacentes, comunidades de bienes y demás Entidades que, carentes de personalidad jurídica, ejerzan las actividades que originen el hecho imponible».

59 J. I. RUBio de UrQuiA, El Impuesto sobre Actividades Económicas, ob. cit., p. 392.

60 A. Menéndez Moreno, El concepto juridico tributario de profesional, IEF, Madrid, 1986, p. 206.

No obstante, este autor se considera crítico con la existencia de las actividades profesionales como actividades diferenciadas de las actividades empresariales, al señalar que aunque «existen actividades que han de diferenciarse a efectos de su régimen tributario (caso de las prestaciones dependientes e independientes), hay otras que a nuestro modo de ver y dada su semejante naturaleza económica no merecían esa diferenciación (las actividades profesionales, empresariales, artísticas y demás explotaciones económicas). Establecido por el Derecho positivo en algún aspecto un régimen tributario diferenciado entre las últimas actividades mencionadas, debemos recurrir, para deslindar el concepto de profesional de estas otras actividades, no a criterios económicos, en los que no se encuentran diferencias, sino a otros de carácter sociológico, que resultan más sutiles, más imperceptibles, y en definitiva necesariamente más insatisfactorios e inseguros, para el ámbito jurídico tributario"s. 


\section{a) Consideraciones respecto del sujeto que presta el servicio profesional}

Aunque la persona física individual sea la idónea para el desarrollo de las actividades profesionales, se considera admisible el ejercicio asociado de actividades profesionales, siempre que cada persona física integrante de la entidad reúna los requisitos necesarios, tales como titulación, colegiación, etc.

Se atribuye a quien desempeña una actividad profesional una preparación intelectual o técnica adecuada. Esta preparación, que estará vinculada al estudio como medio adecuado para conseguirla, vendrá normalmente refrendada por la pertinente habilitación y titulación.

Otras características que acompañarán, con frecuencia, al sujeto que ejerce una actividad profesional serán la habitualidad en el ejercicio y el ánimo de lucro. La habitualidad en el ejercicio de una actividad profesional significa repetición, reiteración, permanencia en el ejercicio. No tiene por qué necesariamente llevarse a cabo de forma continuada, es decir, podrá ser periódica en el sentido de que se repetirá regularmente, no considerándose, por tanto, actividades profesionales las que se ejerzan con carácter ocasional.

En cuanto al ánimo de lucro, el ejercicio de la actividad profesional tendrá por finalidad la obtención de un beneficio, que es predicable de la actividad general del profesional y no de todas y cada una de las actuaciones concretas.
b) Consideraciones respecto del objeto o naturaleza del servicio profesional

En cuanto modalidad de prestación de servicios, se consideran operaciones típicas de los profesionales las que tienen por objeto el trabajo y no los bienes, de forma que su actividad no se materializa en mercancías. No tendrán el carácter de actividad profesional, aunque así se considere en la normativa vigente, aquellas actividades de gestión y mediación que no requieran unos conocimientos de los señalados anteriormente.

c) Consideraciones respecto de la forma de prestar el servicio
profesional

La actividad profesional ha de prestarse de forma independiente, característica ésta que, para determinar su significado, habrá de tenerse en cuenta: 
a) Desde el punto de vista jurídico laboral, la independencia se contrapone a la noción de dependencia, la cual tiene los siguientes caracteres:

- El trabajador pone a disposición del empleador su fuerza de trabajo para aplicarla en interés de éste.

- El trabajador normalmente se incorpora a la empresa.

— En la relación laboral no se suelen delimitar las concretas prestaciones que llevará a cabo el trabajador.

- Como manifestaciones jurídicas de carácter formal del régimen de dependencia lo serán la existencia de un contrato laboral entre el trabajador y el empleador, y el sometimiento al régimen general de la Seguridad Social.

b) Para la delimitación del concepto de independencia tiene una trascendencia especial la dimensión económica. En este sentido, ejerce de forma independiente quien, junto a su propio trabajo, proporciona o aporta los medios de toda índole, y entre ellos los económicos, necesarios para la prestación del servicio profesional. El hecho de que la actividad profesional presente un marcado carácter intelectual tendrá su reflejo en que, aun cuando la prestación de forma independiente suponga la aportación conjunta de capital y trabajo, en el caso del servicio profesional tendrá preponderancia el trabajo cualificado, lo cual conllevará que no habrá necesidad de aportar un capital cualitativamente importante, ni tendrá por qué existir una organización de gran complejidad, como tiene lugar, normalmente, en las actividades empresariales.

\section{Concepto de actividades artísticas}

Según la Regla 3. ${ }^{a} 4$ de la Instrucción para la aplicación de las Tarifas del IAE, «tienen la consideración de actividades artísticas las clasificadas en la Sección 3. ${ }^{a}$ de las Tarifas». Por consiguiente, no se establece un concepto de actividades artísticas, sino que se recurre al fácil, frecuente y poco riguroso criterio descriptivo a través de la enumeración de las actividades.

Sin embargo, en la normativa que regulaba la Licencia Fiscal de Actividades Profesionales y Artísticas sí se definían de forma expresa, en el artículo 294 del Real Decreto Legislativo 781/1986, de 18 de abril, al señalarse: «Tendrán la consideración de artistas a los efectos de este im- 
puesto las personas que individualmente o formando parte de agripaciones actúen mediante retribución en locales públicos o privados, constituyendo o formando parte de un espectáculo o deporte, así como aquellas cuyas actuaciones de carácter recreativo sean transmitidas a través de aparatos o medios fisicos tales como la radiotelefonía, cinematografia, televisión, grabaciones magnetofónicas y discos gramofónicos.

No tendrán a estos efectos la consideración de artistas aquellas personas cuyos trabajos no trasciendan directamente al público, por ser meramente preparatorios o auxiliares de los espectáculos de deportes.»»

Por otra parte, aunque algunos autores, como IRALA GALÁN y MuÑIZ GARCIA ${ }^{61}$, consideran que las actividades artísticas sólo las pueden ejercer las personas físicas, la DGCHT, en diversas contestaciones a consultas, se ha pronunciado en sentido contrario, admitiendo que las personas jurídicas o entes del artículo 33 de la Ley General Tributaria pueden ejercer dichas actividades ${ }^{62}$. Criterio éste que es compartido, entre otros, por PAGÈS I GALTÉs ${ }^{63}$.

En cuanto a la Licencia Fiscal de Actividades Profesionales y Artísticas, MENÉNDEZ MORENO señaló: «Aunque la distinción haya perdido relevancia actualmente por la existencia de unas tarifas comunes de licencia fiscal, las actividades profesionales y las denominadas tributariamente artísticas cabe diferenciarlas también por su objeto, consistiendo éstas en actividades de recreo, esparcimiento o diversión» ${ }^{64}$.

\section{A MODO DE CONCLUSIÓN}

\section{El IAE y el principio de capacidad económica}

Respecto a las relaciones del IAE con el principio de capacidad económica, opinamos que la regulación actual de este impuesto supone una cla-

\footnotetext{
61 Según J. A. Irala Galán y L. A. MuÑiz Garcia, «las Tarifas contienen: orientación sobre lo no especificado en la legislación general o en la propia Instrucción. (Así, por ejemplo, el que los artistas a que se refiere la Sección 3. ${ }^{a}$ de las Tarifas han de ser personas fisicas, se desprende del propio contenido de dicha Sección)». Véase: Impuesto sobre Actividades Económicas, Organismo Autónomo Provincial de Gestión Tributaria de Alicante, 1991, p. 187.

62 Véanse Contestaciones de 5 de noviembre de 1991 y de 5 de mayo de 1992.

63 J. Pagès I Galtés, «El Impuesto sobre Actividades Económicas», ob. cit., p. 777.

64 A. Menéndez Moreno, El concepto juridico tributario de profesional, IEF, Madrid, 1986, p. 209.
} 
ra vulneración de dicho principio constitucional. Consideramos que carece de sentido sostener argumentos sin consistencia, como el afirmar que resulta indiferente que se obtengan o no beneficios en el desarrollo de las actividades económicas, debido a que el hecho imponible del IAE se produce por el mero ejercicio de las citadas actividades.

El objeto del tributo, en el caso de los impuestos que gravan la obtención de ingresos, ha de ser, a nuestro juicio, además de un ingreso neto, un ingreso cierto y real. En consecuencia, se deberían rechazar los ingresos presuntos y los de carácter ficticio.

Por tanto, consideramos que el objeto del tributo en el IAE no puede ser otro que el ingreso neto y cierto que se obtiene como consecuencia del ejercicio de la actividad. Además, resulta, en cierto modo «sorprendente», que si por medio de otros impuestos - IRPF o IS - se puede conocer el beneficio real que obtienen los empresarios o profesionales, no se quiera aprovechar esta información para la cuantificación del IAE.

En cuanto al hecho imponible del IAE - el mero ejercicio de una actividad económica-, podemos señalar que es el único de los que conforman la imposición directa, en el cual no se pone de manifiesto de forma inmediata la capacidad económica del contribuyente. A nuestro juicio, el hecho imponible de un impuesto como el IAE no puede ser otro que la obtención de beneficios procedentes de una actividad económica, por lo que podemos afirmar que estamos en presencia de un hecho imponible, que desconoce las técnicas del actual Derecho tributario y que, en consecuencia, debería ser modificado.

Hemos de poner de manifiesto que no logramos entender cómo por el hecho de ejercer una actividad económica que dé lugar a pérdidas se genere un tributo con el que se tenga que contribuir al sostenimiento de los gastos públicos. El principio de capacidad económica, que tendría que ser el fundamento y límite de la imposición, parece que se ha olvidado por completo en la regulación del IAE.

Resultan de especial interés las consideraciones que, con relación al principio de capacidad económica, ha efectuado CASADO OlLERO, a nuestro juicio, con total acierto. Para este autor, la esencia del principio de capacidad económica exige que dicha capacidad, además de presupuesto legitimador del tributo, sea también presupuesto legitimador de cada acto concreto de imposición, puesto que si así no se hiciese se estaría atentando contra la justicia tributaria, que no puede entenderse cumplida con la alusión a que en la «normalidad de los casos» los efectos negativos 
contrarios a la Constitución no se producirian, ya que dicho criterio «no puede esgrimirse con éxito para ignorar aquellas situaciones particulares en las que, justamente, la tutela constitucional debe mostrarse especialmente operativa» 65 .

En lo que se refiere a la cuantificación del IAE, podemos decir que ésta carece de toda lógica. Incluso en el supuesto de gravarse beneficios ciertos y no presuntos, la tributación del beneficio empresarial resultaria a todas luces más que desproporcionada.

En el caso de gravarse beneficios ciertos, si tenemos en cuenta que la cuota de tarifa puede llegar hasta el 15 por 100 de dichos beneficios, y a esto le añadimos el coeficiente de población (máximo 1,9) y el coeficiente de situación (máximo 2), nos daría una cuota tributaria de hasta el 57 por 100 del beneficio cierto. A lo que habría que sumarle el recargo provincial (máximo 40 por 100 de la cuota de tarifa), con lo que se podría llegar hasta una deuda tributaria de un 63 por 100 del beneficio cierto de la actividad empresarial.

$\mathrm{Si}$, además, tenemos en cuenta que dicho beneficio empresarial ya ha sido gravado por medio de los impuestos estatales (IRPF o IS), y que la integración del IAE con estos impuestos no se produce a través de la deducción en la cuota, sino que se le considera como un gasto deducible en la base, no sería demasiado arriesgado afirmar que este impuesto tiene un alcance confiscatorio.

Debemos poner de manifiesto que si se pretende que este impuesto subsista, resulta ineludible que se corrijan las graves controversias que el mismo presenta con relación a dicho principio. Esto es, tener en cuenta los supuestos en que no exista capacidad económica y eliminar la doble imposición interna que este impuesto ocasiona. Se trata, en definitiva, de la integración de este impuesto en el sistema tributario español, al originar una doble imposición del beneficio empresarial ${ }^{66}$.

${ }^{65}$ G. CASADO OlLERO, «El principio de capacidad económica y el control constitucional de la imposición indirecta. El contenido constitucional de la capacidad económica», en Civitas REDF, n. ${ }^{\circ} 34$, 1982, p. 197.

${ }^{66}$ En este sentido, CHECA GonZÁlez señala: «En general, el atentado más grave al principio de capacidad económica se produce por la circunstancia de que gran parte de las figuras tributarias locales constituyen pura y simplemente una sobreimposición con otros impuestos existentes a nivel estatal. Así ocurre, por ejemplo, con el IBI, siendo así que la propiedad de los bienes inmuebles ya está gravada en el Impuesto sobre el Patrimonio y aun en el IRPF a través de la denostable ficción de la renta imputada; con el IAE, que grava actividades empresariales, profesionales y artísticas ya sujetas a tributar en los respectivos impuestos sobre la renta». Véase: «La transgresión de principios constitucionales en aras a conseguir la suficiencia financiera en las Haciendas Locales», en Impuestos, vol. II, 1991, p. 278. 


\section{EI IAE y el principio de generalidad tributaria}

El IAE nació con un marcado carácter de generalidad, el cual viene implícito en la propia denominación del mismo, frente a los impuestos que sustituye, los cuales hacían referencia a las actividades comerciales e industriales, por un lado, y profesionales y artísticas, por otro.

Sin embargo, el carácter inicial de generalidad que presentó el IAE, y la equiparación entre las distintas actividades económicas, se vio pronto limitado por diversas normas que, en primer lugar, establecieron diferencias entre las actividades agrícolas, ganaderas, forestales y pesqueras, con relación al resto de las actividades. Y en segundo lugar, produjeron la exclusión de la sujeción de las actividades agrícolas, ganaderas dependientes, forestales y pesqueras, quedando únicamente sometida a gravamen la actividad ganadera independiente.

En este sentido, la Disposición Transitoria 4. a de la Ley 5/1990, de 29 de junio, de medidas en materia presupuestaria, financiera y tributaria, aplazó un año el comienzo de aplicación del impuesto para las actividades agrícolas, ganaderas, forestales y pesqueras, esto es, hasta el 1 de enero de 1992. Asimismo, se preveía la aprobación de la Instrucción y Tarifas para estas últimas, distintas a las del resto de las actividades.

Posteriormente, la Ley 6/1991, de 11 de marzo, modifica parcialmente el IAE y dispone el comienzo de su aplicación el 1 de enero de 1992. En esta Ley se modifica el artículo 79.2 de la LRHL, excluyéndose definitivamente del hecho imponible de este impuesto el ejercicio de las actividades agrícolas, ganaderas dependientes, forestales y pesqueras; manteniendo, sin embargo, la tributación de las actividades ganaderas independientes.

A nuestro juicio, el no someter a gravamen a las actividades agrícolas, ganaderas dependientes, forestales y pesqueras, constituye un supuesto de infracción del principio de generalidad tributaria.

Ello se debe a que tal ausencia de gravamen carece de justificación, puesto que, como ha señalado RUBIO DE URQUía, la exclusión del hecho imponible del IAE de dichas actividades se produce de forma arbitraria y sin ningún fundamento técnico, no teniendo otras motivaciones que las de carácter político ${ }^{67}$.

67 J. I. RuBIo de UrQuiA, El Impuesto sobre Actividades Económicas, ob. cit., p. 66. 
Aunque en el artículo 79 de la LRHL se considere el ejercicio de tales actividades como supuestos de no sujeción, creemos que se trata de auténticas exenciones ${ }^{68}$. Por tanto, la crítica la podemos realizar, en cuanto que no se ha establecido ningún fundamento que justifique dicha exclusión.

Por otra parte, volvemos a recordar que si se considera que las actividades agrícolas, ganaderas dependientes, forestales y pesqueras deben excluirse de tributación, resulta contradictorio con la propia naturaleza del IAE como un impuesto censal, que los sujetos pasivos que realicen dichas actividades no tengan que darse de alta en la Matrícula, puesto que, de este modo, se podría llevar un control con relación a otros impuestos.

Este hecho nos saca de dudas, de forma inequívoca, acerca de la confusión a que nos ha querido conducir el legislador, al hacer hincapié en el carácter censal del IAE. En lo que a nosotros respecta, no existen tales dudas, el IAE sólo tiene un objetivo: el recaudatorio.

\section{EI IAE y el principio de igualdad tributaria}

Las críticas que, a nuestro juicio, se podrían realizar con relación a la adecuación del IAE al principio de igualdad tributaria serían, entre otras, las siguientes:

\section{A. Las actividades empresariales, profesionales y artísticas y el principio de igualdad tributaria}

Debemos comenzar indicando que nos mostramos contrarios a la diferenciación entre actividades empresariales, profesionales y artísticas. Únicamente deberían existir, en nuestra opinión, las actividades empresariales, sin perjuicio de que, dentro de las mismas, se distinguiesen los servicios profesionales o los servicios que presten los artistas. Ello es consecuencia de que tanto las actividades profesionales como las activi-

\footnotetext{
68 El hecho imponible del IAE consiste en el mero ejercicio de una actividad económica. A tenor del artículo 80 de la LRHL, se considera que una actividad se ejerce con carácter empresarial, profesional o artístico, cuando suponga la ordenación por cuenta propia de medios de producción y de recursos humanos o de uno de ambos, con la finalidad de intervenir en la producción o distribución de bienes o servicios. Estos requisitos se dan igualmente en el ejercicio de las actividades agrícolas, ganaderas dependientes, forestales y pesqueras. Por consiguiente, consideramos que se trata de actividades exentas del IAE.
} 
dades artísticas constituyen, realmente, modalidades de actividades empresariales.

Esa diferenciación ha originado, en nuestra opinión, que las actividades profesionales y artísticas reciban un tratamiento de favor, lo que vulnera el principio de igualdad, al no existir justificación alguna.

Este tratamiento de favor que reciben las actividades profesionales y artísticas se manifiesta en varios aspectos. En primer lugar, por la cuantificación de estas actividades a través de cuotas fijas, sin tenerse en cuenta la dimensión de estas actividades, con lo que no existe posibilidad de un mayor gravamen como ocurre con las actividades empresariales ${ }^{69}$. Estas situaciones son contrarias al principio de igualdad, puesto que discriminan favorablemente a manifestaciones reveladoras de una mayor capacidad económica, frente a capacidades económicas inferiores. En segundo lugar, otro tratamiento de favor —en este caso únicamente de las actividades profesionales con relación a las actividades empresariales- tiene su origen en el apartado 3 de la Regla 3. ${ }^{a}$ de la Instrucción. En dicho apartado se establece que cuando una persona jurídica o una entidad de las previstas en el artículo 33 de la Ley General Tributaria ejerza una actividad clasificada en la Sección 2. ${ }^{a}$ de las Tarifas (actividad profesional), deberá matricularse y tributar por la actividad correlativa o análoga de la Sección 1. ${ }^{\mathrm{a}}$ de aquéllas (actividades empresariales). Este precepto, que carece de fundamento, da lugar a que los entes anteriores tributen siempre por actividades empresariales. La discriminación se produce porque las Tarifas prevén para estas últimas actividades unas cuotas muy superiores a las de las actividades profesionales, por lo que se produce de nuevo, en nuestra opinión, otra vulneración del principio de igualdad.

\section{B. Los módulos indiciarios y el principio de igualdad tributaria}

Por otra parte, en el seno de las propias actividades empresariales, creemos que tampoco se respeta en sus justos términos el principio de igualdad tributaria. Ello se debe a que los módulos indiciarios utilizados difieren notablemente de unas actividades a otras, junto con la existencia

\footnotetext{
69 Ya había puesto de manifiesto Poveda Blanco, con relación a la Licencia Fiscal de Actividades Comerciales e Industriales: «A nadie se le oculta que la utilización de cuotas fijas representa una forma de graduar la prestación impropia de un sistema fiscal desarrollado y contraria a los objetivos de redistribución de la renta, a la vez que denota la ausencia de aplicación del principio de capacidad económica como criterio de justicia material tributaria». Véase: «Licencia Fiscal de Actividades Comerciales e Industriales; criterios y técnicas de valoración», en Crónica Tributaria, n. ${ }^{\circ} 46$, 1983.
} 
- como acabamos de ver- de cuotas fijas en algunas actividades empresariales ${ }^{70}$.

Quizá hubiese sido más lógico, a nuestro entender, intentar aproximar dentro de lo posible los módulos indiciarios de todas las actividades empresariales. Existe, en este sentido, un módulo que, o bien tendría que haber estado presente en la cuantificación de todas las actividades, o bien en la de ninguna, como sería el «número de empleados». Y no dejarlo reducido únicamente a las actividades extractivas e industriales, a través del «número de obreros», esto es, empleados afectos directamente a la producción.

En definitiva, se puede comprobar cómo no se gravan todas las actividades del mismo modo. La función de los módulos indiciarios es aproximar lo más posible el beneficio presunto al beneficio real que se produce en el ejercicio de la actividad.

Por consiguiente, creemos que se infringe el principio de igualdad, puesto que para determinar el beneficio presunto de las actividades económicas, unas actividades tienen más en cuenta que otras la dimensión de las mismas, y esta circunstancia se produce, a nuestro juicio, de forma injustificada.

Así, podemos comprobar cómo las actividades industriales, para determinar el beneficio presunto, utilizan tres módulos indiciarios (número de obreros, potencia instalada y superficie del local), mientras que las actividades de comercio minorista, únicamente utilizan dos (población de derecho y superficie del local).

\section{EI IAE y la doble imposición interna}

Esta doble imposición interna se produce, debido a que el objeto del tributo en el IAE es una parte del beneficio medio presunto de la actividad, aunque el hecho imponible lo constituya el mero ejercicio de

\footnotetext{
${ }^{70}$ Con relación a la Licencia Fiscal de Actividades Comerciales e Industriales, Poveda Blanco criticaba los procedimientos seguidos para la evaluación de las cuotas por las que se pretendía gravar los rendimientos medios de la actividad y presuntos, al señalar que «en la medida en que esta investigación se ha realizado sobre muestras de poblaciones reducidas que constituyen una insuficiente visión del colectivo y porque el procedimiento de cálculo de los rendimientos ha sido diferente entre las diversas actividades, irregular en su tratamiento y hasta inexistente en algunos casos, denotando una ausencia clara de rigor cientifico». Véase: «Licencia Fiscal de Actividades Comerciales e Industriales; criterios y técnicas de valoración», en Crónica Tributaria, n. ${ }^{\circ} 46,1983$, p. 130.
} 
una actividad económica en territorio nacional. En consecuencia, el beneficio procedente del ejercicio de actividades económicas resulta gravado, además de por los impuestos estatales del IRPF y del Impuesto sobre Sociedades, por el Impuesto municipal sobre Actividades Económicas.

El mecanismo actual para atenuar la doble imposición interna, consistente en la consideración del IAE como gasto deducible de la base imponible del IRPF y del Impuesto sobre Sociedades, resulta a todas luces insuficiente. De ahí que, para conseguir un mayor grado de integración, sea necesario acudir a la deducción del IAE en la cuota del IRPF y del Impuesto sobre Sociedades.

Sin embargo, a través de este último mecanismo no se resuelven todos los problemas, puesto que la deducción en cuota eliminaría la responsabilidad política del Municipio, al soportar el presupuesto estatal la carga del impuesto, además de impedir a los contribuyentes con cuota estatal insuficiente poder practicar esta deducción.

Para solucionar el primer problema, sería necesario que no fuese excesivamente elevado el margen de opción de los coeficientes municipales de población y de situación, sin que por ello se vean afectados los principios de autonomía y suficiencia financiera locål. En consecuencia, toda la tributación por el IAE debería ser deducible de la cuota de los impuestos estatales del IRPF y del Impuesto sobre Sociedades. En cuanto a la imposibilidad de poder deducir lo pagado por el IAE, por insuficiencia de cuota en el IRPF y en el Impuesto sobre Sociedades, estaríamos ante una situación similar a la que se produce con relación al Impuesto sobre el Incremento del Valor de los Terrenos de Naturaleza Urbana, en la que el IAE se configuraría como un tributo mínimo, cuya deducibilidad dependería de cuál fuese la cuota en los mencionados impuestos estatales.

Sin embargo, en los casos de aquellas actividades económicas que resulten con pérdidas - demostrándose mediante la contabilidad del sujeto pasivo- - y que, además, resulte cuota insuficiente en los impuestos estatales para poder deducir lo pagado por el IAE, creemos que se debería arbitrar el mecanismo para que los Municipios devolviesen lo pagado en concepto de IAE. De este modo, se produciría una mayor adecuación de dicho impuesto al principio de capacidad económica, evitando que se produzcan situaciones que se pudiesen calificar de insostenibles. 


\section{Recapitulación final}

Por último, indicar que el IAE, a pesar de las mejoras que sobre el mismo se realicen - las cuales son necesarias y, por tanto, deben llevarse a cabo de forma ineludible-, continuará siendo un impuesto muy problemático por su difícil adaptación al principio de capacidad económica.

En definitiva, en el IAE se han antepuesto, de un modo que sin lugar a dudas resulta, cuanto menos discutible, los principios de autonomía y suficiencia financiera local al principio de capacidad económica. 
